\title{
CONTROVÉRSIAS SOBRE A ANUNCIADA REDUÇÃO DA EXPLORAÇÃO DO TRABALHO INFANTIL NO BRASIL E EM SANTA CATARINA
}

\section{LES CONTROVERSES A PROPOS DE LA RÉDUCTION DE L'EXPLOITATION DU TRAVAIL DES ENFANTS AU BRÉSIL ET À SANTA CATARINA}

Maria dos Anjos Viella* Soraya Franzoni Conde**

Resumo: O objetivo deste texto é problematizar a redução de $42 \%$ no número de crianças trabalhadoras no Brasil, anunciada pelo governo federal entre os anos 1995 a 2002, segundo o Mapa de Indicativos do Trabalho da Criança e do Adolescente no Brasil (2005), fazendo o seguinte percurso: descrição das características do trabalho infantil no Brasil e em Santa Catarina, apresentação de argumentos que demonstram que a redução propagada é enganosa e aparente; problematização dos procedimentos metodológicos utilizados e dos limites da fiscalização do Ministério do Trabalho. Apresentamos detalhadamente as atividades realizadas por crianças e os municípios onde elas acontecem, concluindo que alardear a redução sem considerar o aumento da diversificação das atividades desenvolvidas pelas crianças na atualidade, coerentemente com as atuais transformações no mundo do trabalho, é questão controversa. As crianças não estão mais no chão da grande indústria, mas têm trabalhado em inúmeras atividades invisíveis à fiscalização, decorrentes das novas formas do trabalho coletivo.

Palavras-chave: Infância. Desigualdades sociais. Trabalho infantil. Transformações no mundo do trabalho. 
Résumé: Lobjectif de ce texte est de problématiser l'annonce par le gouvernement fédéral d'une réduction du nombre d'enfants travailleurs au Brésil (42\%) dans la période 1995 à 2002. Sur la base de la "Carte des Indicateurs sur le Travail des Enfants et des Adolescents au Brésil” (2005) nous avons utilisé la démarche suivante: description des caractéristiques du travail des enfants au Brésil et à Santa Catarina, présentation des arguments qui démontrent que la réduction propagée est trompeuse et apparente; questionnement des procédures méthodologiques utilisées et les limites de la tutelle du Ministère du Travail. Nous présentons en détail les activités menées par les enfants et les municipalités où elles sont réalisées, en concluant que prétendre à une réduction sans tenir compte de la diversification accrue des activités pour les enfants aujourd'hui, avec les transformations actuelles dans le monde du travail, est une question très controversée. Les enfants ne sont plus dans la grande industrie, mais ils ont travaillé dans de nombreuses activités “invisibles", qui échappe à la surveillance, compte tenu des nouvelles formes de travail collectif.

Mots-clés: Enfance. Inégalités sociales. Travail des enfants. Transformations dans le monde du travail. 
"O essencial é invisível aos olhos"

(Antoine de Saint-Exupéry)

\section{Introdução ${ }^{2}$}

Cotidianamente, deparamo-nos com cenas de crianças trabalhando nas mais variadas atividades econômicas: agricultura, coleta de materiais recicláveis, extração de pedras, guarda de carros, auxílio em matadouros, office-boy e office girl, produção de artefatos para as indústrias, reciclagem, transporte, venda de bugigangas nas ruas, venda de drogas, venda de picolés, entre tantas outras. Essas cenas podem ser visualizadas em diferentes regiões do país aparecendo desde as capitais dos estados aos pontos mais desconhecidos dos mapas: Simolândia, Poxoréo, Quipapá, Talismã, Mira-estrela, Moita Bonita, Serra do Navio, Terra Boa, Céu Azul, Solidão, Desterro, São João Batista, Lages, Tijucas, Urubici, Orleans, Taió ${ }^{3}$.

As diferentes formas e espacialidades em que encontramos crianças trabalhando desafiam nossas análises questionam os anúncios oficiais sobre a redução do trabalho infantil no Brasil e expressam o avanço das desigualdades sociais inerentes à forma capitalista de produção. Segundo Frei Betto (2010), o Brasil é um país rico, porém injusto. O relatório da ONU aponta o país com o terceiro pior índice de desigualdade social do mundo. Embora as políticas sociais de transferência de renda tenham sido um dos focos do governo federal, a desigualdade social continua se propagando entre as futuras gerações. Segundo a ONU, 58\% da população brasileira matem o mesmo perfil social de pobreza entre duas gerações. Em relação à exploração da força de trabalho infantil, 
os dados não são diferentes. Embora o governo federal propague sua redução, uma análise cuidadosa com cruzamento de dados de fiscalização evidencia a impossibilidade de afirmar a redução desse vergonhoso problema que insiste em revelar a face cruel da exploração capitalista em sua periferia. Há de se estranhar que em um mundo de tantas tecnologias, riqueza e desemprego, crianças ainda tenham de trabalhar. Se para muitos, falar de trabalho infantil remete as cenas dos séculos XVIII e XIX, os dados da PNAD (2005) revelam que pelo menos 5,1 milhões de crianças e de adolescentes (entre 5 e 18 anos) trabalham no Brasil, o que representa $11,5 \%$ da população na faixa etária correspondente. Das crianças e dos adolescentes ocupados, $41,4 \%$ estão inseridos em trabalhos agrícolas; proporção que chega a 62,6\% entre 5 e 13 anos.

Ainda segundo Betto (2010), a cada cem habitantes brasileiros, apenas nove possuem diploma universitário e se perguntarmos aos 91 que não concluem o ensino superior os motivos que os fizeram parar de estudar, o trabalho precoce aparecerá em grande proporção. Há 25 anos metade da renda total do país está nas mãos dos $10 \%$ mais ricos. E os 50\% mais pobres dividem $10 \%$ da riqueza nacional. No campo, os dados são ainda mais assustadores, pois mais da metade da população do país detém 3\% das propriedades rurais e apenas 46 mil proprietários são donos de metade das terras, permanecendo a mesma estrutura fundiária do Brasil império!

Refletindo sobre os avanços da desigualdade social e dos conflitos decorrentes do desenvolvimento do capitalismo, Silver (2005) afirma que "para onde vai o capital, o conflito vai atrás". Ou seja, onde o capitalismo avança, as contradições como desemprego, trabalho infantil, miséria e conflitos sociais avançam na mesma 
proporção. Diante de tal situação, será possível concordar com a diminuição da exploração do trabalho infantil anunciada pelo governo federal? A análise que realizamos dos Mapas de Indicativos do Trabalho da Criança e do Adolescente de $2005^{4}$ permite apreender a exploração do trabalho infantil como expressão das novas formas do trabalho coletivo que desafiam teorias, pesquisadores e auditores fiscais do trabalho. Nesse sentido, alardear a redução do trabalho infantil é algo controverso.

\section{A redução anunciada pelos Mapas de Indicativos $2005^{5}$ e o Relatório Global da OIT/2006 6}

O Mapa de Indicativos do Trabalho Infantil publicado em $2005^{7}$, considerado para análise, é dividido em três módulos. No Módulo I detalha a situação do trabalho da criança e do adolescente no Brasil, por regiões, considerando os seguintes aspectos: série histórica (1995-2002) da taxa de trabalho infantil nacional; variação do trabalho infantil por unidades da federação de 1999 a 2002, abrangendo a faixa etária de cinco a 15 anos; distribuição segundo as regiões e unidades da federação do Brasil; relação entre trabalhadores infantis e a população do mesmo grupo etário, segundo as regiões do país; distribuição do trabalho infantil segundo as áreas geoeconômicas; distribuição do trabalho infantil segundo as posições na ocupação (não remunerados, empregado, empregador, trabalho domiciliar, autoconsumo etc.); distribuição do trabalho infantil segundo sexo e grupos etários; distribuição do trabalho infantil segundo raça, cor e grupos etários; relação entre trabalho infantil e frequência escolar; rendimento do trabalho in- 
fantil segundo trabalho principal da faixa etária de dez a 15 anos; rendimento do trabalho infantil segundo as posições na ocupação por terceiros (empregados ou trabalho doméstico).

O Módulo II apresenta as condições de trabalho e as repercussões à saúde. O Módulo III traz informações sobre indicativos de trabalho em atividades ilícitas (exploração sexual comercial infantil, narcotráfico e narcoplantio) nas unidades da federação. Para o propósito desse texto, será analisado mais detidamente o Módulo I por ser aquele que aborda a questão da redução do trabalho das crianças.

Considerando as estimativas presentes nos gráficos e nas tabelas do Mapa, todas elas apresentam e reafirmam constantemente a redução com algumas nuances de pequeno aumento, mas, no geral, o que prevalece é o discurso da redução. O Gráfico I, que compõe o módulo I, ao trazer a série histórica (1995-2002) da taxa de trabalho infantil nacional, afirma que ocorreu redução de 41,95\% no número de crianças e adolescentes trabalhando na faixa etária de cinco e 15 anos. Quando essa série histórica é desagregada afirma-se também a redução nos anos de 1995 a 1998. O período de 1999 a 2001 destaca-se como o de maior índice de redução na série histórica analisada e, entre os anos 2001 e 2002, também houve decréscimo em quase todos os Estados, salvo três exceções:

O Gráfico II vai apontar os estados de Alagoas, Rio Grande do Norte e Rio de Janeiro como únicos estados que apresentaram crescimento no período considerado (1999 a 2001).

$\mathrm{Na}$ análise dos Mapas, percebemos que o discurso da diminuição do trabalho infantil aparece reiteradas vezes, o que chama 
nossa atenção. A redução é também anunciada no Relatório Global da OIT/2006: O fim do trabalho infantil, um objetivo ao nosso alcance, ${ }^{8}$, e no Suplemento Brasil ${ }^{9}$ desse documento, tem-se o quadro a seguir:

Quadro 1 - Estimativas das diferentes categorias de trabalho infantil por idade: 2000-2004

\begin{tabular}{|c|c|c|c|c|c|c|c|c|c|}
\hline \multicolumn{2}{|c|}{$\begin{array}{c}\text { Escalão etário } \\
\text { (anos) }\end{array}$} & \multicolumn{2}{|c|}{$\begin{array}{c}\text { População } \\
\text { infantil }\end{array}$} & \multicolumn{2}{c|}{$\begin{array}{c}\text { Da qual: crianças } \\
\text { economicamente } \\
\text { ativas }\end{array}$} & \multicolumn{2}{|c|}{$\begin{array}{c}\text { Da qual: } \\
\text { crianças } \\
\text { trabalhadoras }\end{array}$} & \multicolumn{2}{|c|}{$\begin{array}{c}\text { Da qual: } \\
\text { crianças em } \\
\text { trabalhos } \\
\text { perigosos }\end{array}$} \\
\hline $\begin{array}{c}\text { Total } \\
5-17\end{array}$ & $\begin{array}{c}\text { Número } \\
\text { (milhões) }\end{array}$ & 2000 & 2004 & 2000 & 2004 & 2000 & 2004 & 2000 & 2004 \\
\hline $5-14$ & $\begin{array}{c}\text { Número } \\
\text { (milhões) }\end{array}$ & 1.194 .4 & 1.206 .5 & 211.0 & 211.0 & 186.3 & 165.8 & 111.3 & 74.4 \\
\hline $5-17$ & $\begin{array}{c}\text { Número } \\
\text { (milhões) }\end{array}$ & 332.0 & 359.8 & 140.9 & 140.9 & 59.2 & 51.9 & 59.2 & 51.9 \\
\hline
\end{tabular}

Fonte: OIT. Relatório Global-2006. A eliminação do trabalho infantil: um objetivo ao nosso alcance, p. 13. (Adaptado por VIELLA, 2008, p. 98).

Segundo o documento:

As novas estimativas sugerem que em 2004 haveria cerca de 317 milhões de crianças economicamente activas, com idades entre os 5 e os 17 anos, das quais 218 milhões poderiam ser consideradas como crianças em situação de trabalho infantil. Destas, 126 milhões realizavam trabalhos perigosos. Os números correspondentes ao escalão etário mais estreito, dos 5 aos 14 anos, são 191 milhões de crianças economicamente activas, 166 milhões de crianças trabalhadoras, e 74 milhões de crianças em trabalhos perigosos. $\mathrm{O}$ número de crianças trabalhadoras, tanto no escalão etário 
dos 5-14 como no dos 5-17 caiu 11 por cento em quatro anos, de 2000 a 2004. Contudo, o declínio foi muito maior entre aquelas que estavam envolvidas em trabalhos perigosos: 26 por cento para o escalão etário dos 5-17, e 33 por cento para os 5 a 14 anos. (OIT apud VIELLA, 2008, p. 98).

Em síntese, o que o relatório traz é que o número de crianças trabalhadoras entre 5 e 17 anos segue apresentando redução. Nos gráficos e números apresentados no relatório há, “[...] uma tendência perceptível de queda do incremento de trabalhadores infantis para todas as idades, exceto para a faixa dos 17 anos, onde há uma tendência de subida desde 2001." (OIT, SUPLEMENTO BRASIL, 2006, p. 6). Nessa direção, apresenta a diminuição por sexo, por situação censitária, por região do país e por Estado apontando que “[...] em números absolutos, as regiões Nordeste e Sudeste são as que mais apresentam trabalhadores infantis". (p. 11).

Entretanto, as estatísticas oficiais divulgadas são contraditórias. Em nota técnica/2006; cujo assunto é análise dos dados sobre o trabalho infantil na PNAD 2005, a Secretaria de Avaliação e Gestão da Informação do Ministério do Desenvolvimento Social e Combate à Fome aponta ligeiro crescimento na Taxa de Ocupação das pessoas entre cinco a 17 anos de idade. Esse aumento na taxa de ocupação é notado na faixa de cinco a nove anos e dez a quatorze e redução na faixa de 15 a 17. Desse modo:

Em termos absolutos, o número de trabalhadores de 5 a 17 anos saltou de 5,3 milhões para 5,45 milhões, no período de 2004 a 2005, ocorrendo um acréscimo de $148 \mathrm{mil}$ crianças. Trata-se de um achado importante por indicar uma tendência de aumento nas taxas, o que não ocorria há muitos anos. [...]. Em termos absolutos, a população de 5 a 17 anos caiu de 45.109 milhões para 44.842 milhões entre 2004 e 2005. Isto vem ocorrendo devido ao efeito da 
redução acelerada do número de filhos por mulher a cada ano. [...]. Embora os meninos respondam por dois terços do total de crianças empregadas em 2005, o maior crescimento dos novos ocupados se deu entre as meninas. (MDS/SAGI, 2006, [s./p.]).

Embora a Nota Técnica/2006 divulgue dados posteriores às pesquisas mencionadas pelo Relatório Global 2006, o Suplemento Brasil ao Relatório Global da OIT - 2006, ao fazer análise das tendências estatísticas de diminuição do trabalho infantil no Brasil, afirma:

Que o trabalho infantil seguirá sua tendência de diminuição nos próximos anos, caso se mantenham e se incrementem as ações e políticas públicas nas áreas de direitos humanos, educação, promoção social, redução da pobreza, trabalho e emprego, e das políticas afirmativas relacionadas aos temas de gênero, raça, etnia, entre outras. (OIT- Suplemento- Brasil: Relatório Global 2006, p. 24).

Em meio a tantas controvérsias, desencontros de cifras e incongruência dos dados, cabe destacar que os dados não falam, mas "permanecem mudos até serem corretamente interrogados" (CASTRO, 2003, [s./p.]). E, quando por nós interrogados, a realidade que se descortina é uma enorme diversificação nas atividades exercidas pelas crianças, por todo o Brasil. Essa diversificação não poderia ser compreendida senão pelas tendências atuais do mundo do trabalho, onde se destaca o aumento do setor de serviços, do trabalho assalariado, subcontratado, terceirizado, "informal" (ANTUNES, 2005; OLIVEIRA, 2003; NAVARRO, 2003; DUPAS, 2000; AUED, 2005), produzido pelo crescimento do desemprego e da desigualdade social do país. 


\section{As denúncias da Superintendência Regional do Trabalho e do Emprego de Santa Catarina (SRTE/SC) ${ }^{10}$}

Na tentativa de localizar qualitativamente a exploração infantil no trabalho, buscando apreender informações para além dos limites dos mapas e das análises governamentais tendenciosas, realizamos uma pesquisa junto à Superintendência Regional do Trabalho e do Emprego de Santa Catarina (SRTE/SC), responsável pela averiguação e fiscalização das condições em que as diferentes formas de trabalho se desenvolvem no Estado. $\mathrm{Na}$ análise dos relatórios, buscamos encontrar o trabalho que, por hora, foi intitulado invisível, com dados não publicados nos Mapas de Indicativos.

A pesquisa abrangeu relatórios de denúncias de trabalho infantil ocorridas entre os anos de 2004 e $2006^{11}$. Nesse período, foram registradas 255 ocorrências de exploração infantil no trabalho. Os relatórios são oriundos de atividades de fiscalização ocorridas a partir de denúncias e de abordagens de rua, referentes à exploração de menores de 16 anos em condições insalubres, perigosas e em jornadas extenuantes, sem possibilidade de aprendizagem profissional. Portanto, a averiguação não atinge o trabalho familiar. As denúncias fiscalizadas referem-se às seguintes ocorrências e municípios: 
Quadro 1 - Municípios fiscalizados pela SRTE e focos de trabalho infantil em Santa Catarina

\begin{tabular}{|c|c|}
\hline Município & Atividades desempenhadas por crianças \\
\hline Água Doce & $\begin{array}{l}\text { Plantação e colheita de morango com jornada de trabalho } \\
\text { diária de } 10 \text { horas e exposição constante a agrotóxicos, ao } \\
\text { sol, ao frio e à chuva; }\end{array}$ \\
\hline Alfredo Wagner & $\begin{array}{l}\text { Plantio e colheita da cebola com jornada de trabalho diá- } \\
\text { ria de } 4 \text { a } 8 \text { horas, exposição a agrotóxicos, manipulação de } \\
\text { instrumentos cortantes e exposição ao sol, ao frio, ao ven- } \\
\text { to e a chuva; trabalho na boleia do caminhão carregando e } \\
\text { vendendo frutas na estrada com jornada diária de trabalho } \\
\text { indefinida e risco de acidentes na estrada; }\end{array}$ \\
\hline Araranguá & $\begin{array}{l}\text { Aplicação de resíduos em fibras com jornada diária de tra- } \\
\text { balho de } 8 \text { horas e exposição a cheiro forte, a produtos quí- } \\
\text { micos e ao sol, ao frio, à chuva e ao vento; }\end{array}$ \\
\hline Balneário Camboriú & $\begin{array}{l}\text { Construção civil com jornada de trabalho diária de } 10 \text { ho- } \\
\text { ras, manipulação de instrumentos cortantes e carregamento } \\
\text { de pesos excessivos; e comércio ambulante nas praias com } \\
\text { jornada de } 6 \text { horas diárias e exposição extenuante ao sol; }\end{array}$ \\
\hline Bombinhas & $\begin{array}{l}\text { Empacotamento em supermercados com jornada de traba- } \\
\text { lho de } 4 \text { horas diárias; }\end{array}$ \\
\hline Braço do Norte & Garçonete com jornada de 4 horas diárias; \\
\hline Brunópolis & $\begin{array}{l}\text { Plantio, colheita e ensaque de cebola em regime familiar, ao } \\
\text { céu aberto e com carregamento excessivo de peso; }\end{array}$ \\
\hline Blumenau & $\begin{array}{l}\text { Pastelarias com jornadas diárias de } 6 \text { horas e exposição a } \\
\text { óleos quentes com risco de queimaduras; }\end{array}$ \\
\hline Caçador & $\begin{array}{l}\text { Plantação de tomate e de cebola com jornada de } 10 \text { horas di- } \\
\text { árias e exposição a agrotóxicos, ao sol e ao frio; viveiro de } \\
\text { animais com jornadas de } 10 \text { horas diárias em locais fétidos } \\
\text { e de condições sanitárias deploráveis; construção civil com } \\
\text { jornadas de } 6 \text { horas diárias e manipulação de instrumentos } \\
\text { perigosos, carregamento de pesos e exposição a poeira ex- } \\
\text { cessiva; rebobinamento de papel higiênico, corte de pinus e } \\
\text { enchimento de sacos de mudas de plantas a céu aberto com } \\
\text { manipulação de instrumentos perigosos; }\end{array}$ \\
\hline
\end{tabular}




\begin{tabular}{|c|c|}
\hline Calmon & $\begin{array}{l}\text { Madeireira com jornada de trabalho diária indeterminada, } \\
\text { exposição ao pó; ao ruído e com manipulação de máquinas } \\
\text { perigosas; }\end{array}$ \\
\hline Canelinha & $\begin{array}{l}\text { Cerâmica com jornada de trabalho diário entre } 8 \text { e } 10 \text { horas, } \\
\text { exposição ao pó, ao forno quente e com manipulação de má- } \\
\text { quinas perigosas; direção de tratores com jornada de } 8 \text { horas } \\
\text { diárias; }\end{array}$ \\
\hline Chapecó & $\begin{array}{l}\text { Classificação de fumo com jornada de trabalho diário de } \\
11 \text { horas e exposição e manipulação de agrotóxicos, instru- } \\
\text { mentos cortantes ao céu aberto; serigrafia com jornada diá- } \\
\text { ria de } 8 \text { horas, manipulação de produtos químicos nocivos } \\
\text { e máquinas perigosas; empacotamento em supermercados; } \\
\text { ensacamento de carvão, garçom, office boy e limpador de } \\
\text { barcos com jornadas de } 8 \text { horas de trabalho diárias e exposi- } \\
\text { ção constante a céu aberto; pizzaiolo com jornada diária de } \\
6 \text { horas de trabalho e exposição constante a calor excessivo } \\
\text { com risco de acidente em forno quente; }\end{array}$ \\
\hline Correia Pinto & $\begin{array}{l}\text { Serraria com jornada diária de trabalho de } 8 \text { horas e ex- } \\
\text { posição ao pó, a ruídos e com manipulação de máquinas } \\
\text { perigosas; }\end{array}$ \\
\hline Criciúma & $\begin{array}{l}\text { Lavação de automóveis com jornadas diárias de trabalho } \\
\text { indeterminadas e risco de acidente de trânsito; }\end{array}$ \\
\hline Cunhaporã & $\begin{array}{l}\text { Acabamento de forro em funerária - ocorrência com dados } \\
\text { incompletos; }\end{array}$ \\
\hline Florianópolis & $\begin{array}{l}\text { Venda ambulante nas praias com jornada de trabalho diária } \\
\text { de } 8 \text { a } 10 \text { horas durante a temporada de verão, expostos ao } \\
\text { sol, ao vento e à chuva; guardadores de carros com jornadas } \\
\text { de trabalho indeterminadas e expostas aos perigos da rua e } \\
\text { do trânsito; }\end{array}$ \\
\hline Gaspar & $\begin{array}{l}\text { Trabalho na produção de produtos químicos com jornada } \\
\text { diária de trabalho indefinida, manipulação de solventes } \\
\text { químicos, com más condições sanitárias e em local mal } \\
\text { ventilado; }\end{array}$ \\
\hline Içara & $\begin{array}{l}\text { Plantação de tomates com jornada de trabalho diária de } 8 \\
\text { horas por dia e exposição constantes aos agrotóxicos, ao sol, } \\
\text { ao vento, ao frio e à chuva; }\end{array}$ \\
\hline
\end{tabular}




\begin{tabular}{|c|c|}
\hline Irani & $\begin{array}{l}\text { Enchimento de tubetes para mudas de plantas ao céu aberto } \\
\text { - ocorrência com informações incompletas; }\end{array}$ \\
\hline Ituporanga & $\begin{array}{l}\text { Plantio e colheita da cebola em regime familiar de jornada } \\
\text { de trabalho diária indeterminada com exposição aos agro- } \\
\text { tóxicos e ao sol, ao frio, à chuva e ao vento; }\end{array}$ \\
\hline Jaguaruna & $\begin{array}{l}\text { Trabalho em tanques de camarão com jornadas de trabalho } \\
\text { de } 8 \text { horas expostos as constantes variações de temperatu- } \\
\text { ras e sem equipamentos de proteção exigidos para atividade } \\
\text { específica; }\end{array}$ \\
\hline Lacerdópolis & $\begin{array}{l}\text { Frentistas de postos de gasolina com jornadas diárias de } 8 \\
\text { horas, manipulação de produtos químicos perigosos e risco } \\
\text { de atropelamento e acidentes de trânsito; }\end{array}$ \\
\hline Lages & $\begin{array}{l}\text { Balcão de padaria em regime familiar e exposição a forno } \\
\text { quente; lavação de carros com jornada de trabalho diária } \\
\text { de } 9 \text { horas - registro incompleto sem informações sobre as } \\
\text { condições de trabalho; plantação de fumo em regime fami- } \\
\text { liar com jornadas indeterminadas e manipulação de agro- } \\
\text { tóxicos e exposição constante a céu aberto; limpeza de pes- } \\
\text { tifício com jornada de quatro horas diárias e manipulação } \\
\text { de máquinas pesadas e perigosas e produtos químicos em } \\
\text { ambiente insalubre; empacotamento de picolés com maqui- } \\
\text { naria pesada e em local mal ventilado; }\end{array}$ \\
\hline Monte Carlo & $\begin{array}{l}\text { Plantio, colheita e ensaque de cebola em regime familiar, ao } \\
\text { céu aberto e com carregamento excessivo de peso; }\end{array}$ \\
\hline Nova Erechim & $\begin{array}{l}\text { Marcenaria com jornadas de trabalho de } 6 \text { horas diárias, } \\
\text { expostos ao pó, ao ruído das máquinas e com manipulação } \\
\text { de instrumentos perigosos; }\end{array}$ \\
\hline Nova Trento & $\begin{array}{l}\text { Garçons encontrados trabalhando na hora do almoço - } \\
\text { ocorrência incompleta; }\end{array}$ \\
\hline Palhoça & $\begin{array}{l}\text { Garçom em bar na temporada de verão - documento in- } \\
\text { completo sem informações adicionais; construção civil com } \\
\text { jornada de } 8 \text { horas e exposição à pó, carregamento excessi- } \\
\text { vo de peso, colocação de mármore e manipulação de instru- } \\
\text { mentos perigosos e cortantes; serviço de chapa }{ }^{12} \text { na Central } \\
\text { de Abastecimento Alimentar (CEASA) com jornada de } 6 \\
\text { horas e carregamento excessivo de peso ao céu aberto; }\end{array}$ \\
\hline
\end{tabular}




\begin{tabular}{|l|l|}
\hline Santa Helena & $\begin{array}{l}\text { Madeireira com jornada de trabalho diária de 6 horas, ex- } \\
\text { posição à pó, ao ruído e à máquina perigosa; }\end{array}$ \\
\hline São João Batista & $\begin{array}{l}\text { Produção de calçados com jornada de trabalho diária entre } \\
6 \text { e } 10 \text { horas em regime familiar de cotas, manipulação de } \\
\text { cola de sapateiro e de instrumentos cortantes perigosos; }\end{array}$ \\
\hline São Joaquim & $\begin{array}{l}\text { Empacotamento em supermercado com jornada de traba- } \\
\text { lho diária de } 8 \text { horas; }\end{array}$ \\
\hline São José & $\begin{array}{l}\text { Madeireira com jornada de trabalho entre 8 e 10 horas, ma- } \\
\text { nipulação de instrumentos cortantes, máquinas perigosas } \\
\text { e exposição ao pó da madeira; serviço de chapa no CEASA } \\
\text { com jornada de 6 horas e carregamento excessivo de peso } \\
\text { ao céu aberto; metalurgia com manipulação de maquinaria } \\
\text { pesada e ruídos excessivos; }\end{array}$ \\
\hline Tijucas & $\begin{array}{l}\text { Olaria com exposição ao pó e ao forno quente e manipula- } \\
\text { ção de máquinas perigosas; }\end{array}$ \\
\hline Videira & $\begin{array}{l}\text { Entrega e venda de jornal na rua com jornada diária de tra- } \\
\text { balho de } 5 \text { horas e exposição aos perigos da rua, do trânsito } \\
\text { e ao céu aberto; venda de balas na rua com jornada de tra- } \\
\text { balho diária indefinida, exposição aos perigos da rua e do } \\
\text { trânsito e ao céu aberto; trabalho na construção civil com } \\
\text { jornada de } 6 \text { a 8 horas e carregamento de peso excessivo, } \\
\text { poeira e ruídos; }\end{array}$ \\
\hline Xaxim & $\begin{array}{l}\text { Lavação de automóveis com jornada diária de trabalho in- } \\
\text { definida realizada na rua à céu aberto e com risco de aci- } \\
\text { dente de trânsito; }\end{array}$ \\
\hline $\begin{array}{l}\text { Trabalho como chapa no Ceasa, ocorrência com dados in- } \\
\text { completos. }\end{array}$ \\
\hline Xanxer
\end{tabular}

Segundo Conde (2007), após o flagrante de trabalho infantil, as crianças são encaminhadas ao Conselho Tutelar, para concessão de bolsas do Programa de Erradicação do Trabalho Infantil (PETI) que lhes proporciona um rendimento mensal de $\mathrm{R} \$ 40,00$ desde que a criança permaneça matriculada numa escola. Por conseguinte, são raros os casos em que se interrompe o trabalho 
da criança, sendo que no melhor dos exemplos, ela passa a frequentar a escola, num período, e, no outro, continua trabalhando.

Entre as ocorrências presentes nos relatórios descritos no quadro 1.0 acima, destacamos informações presentes em alguns relatórios e processos do Ministério Público. No dia oito de julho de 2002, o Conselho Tutelar da cidade de Itajaí/SC, encaminhou ao GECTIPA $^{13}$, à DRT (Delegacia Regional do Trabalho) e à Vara da Infância e da Juventude um documento que registra $o$ atendimento de um adolescente de 15 anos que procurou o Conselho Tutelar da cidade para informar que foi levado à Itajaí para trabalhar e não conseguiu o que lhe foi prometido. A 4a Promotoria de Justiça da Comarca de Itajaí - Curadoria da Infância e da Juventude - requisitou a instauração de inquérito policial a respeito de crime pelo emprego de menores de 18 anos e também a respeito de denúncias acerca do fato de trinta pessoas estarem alojadas em péssimas condições de higiene, incluindo adolescentes menores de 16 anos. Conforme o depoimento do adolescente, ele morava com sua mãe no município de Itararé (SP) e um senhor passou com uma Van na rua onde morava procurando pessoas para trabalharem num serviço onde seriam pagos $\mathrm{R} \$ 20,00$ por dia. Na cidade de Navegantes, o carro pegou mais 12 pessoas, alguns menores de 16 anos. Ao chegarem ao local de trabalho, notaram que dormiriam em local sujo e fétido, em beliches amontoadas e com direito a um banho por dia. Além dos próprios trabalhadores serem os responsáveis pela limpeza do local, eles trabalhavam em chamadas diárias das $6 \mathrm{~h}$ até às $15 \mathrm{~h}$, das $15 \mathrm{~h}$ às $24 \mathrm{~h}$ e das $24 \mathrm{~h}$ às $6 \mathrm{~h}$. Muitas vezes, trabalhavam direto das $6 \mathrm{~h}$ de um dia até às $6 \mathrm{~h}$ do dia seguinte, para recebimento de três diárias. $\mathrm{O}$ trabalho consistia em dobrar os sacos de açúcar, embalar e transportar. Os empregadores descontavam 
do rendimento o almoço, o alojamento e o seguro contra acidentes de trabalho, diferentemente de tudo o que foi prometido.

Os fiscais da SRTE também encontraram denuncias sobre casos de exploração de crianças na extração e no beneficiamento de pedras no estado de Santa Catarina. Conforme atesta o relatório de 25 de novembro de 2005, foram encontradas crianças trabalhando em Camboriú (nos bairros: João da Costa, Rio do Meio, Macacos, Macacos II, Ouvidor, Argal, Nova Esperaça e Morretes) e Itapema (no bairro Morro do Boi).

O trabalho infantil também ocorre nas mais diversas culturas agrícolas do estado de Santa Catarina. Conforme relatório de 10 de outubro de 2005 e a tese de Conde (2012), auditores fiscais encontraram menores de 16 anos, trabalhando na plantação de fumo, em 17 locais do Estado: Rodovia Lino Zanoli, Rodovia José Dermos, Rodovia ICR 252, Linha Anta, Linha Batista, Estrada Geral do Morro da Fumaça (Cocal do Sul), Estação Cocal, Estrada Geral Ronco D'água, Rodovia Mãe Luíza, Rodovia Jorge Lacerda, Rodovia SC 443, Estrada Geral Jorge Fortulino, Estrada Geral Coqueiros, Estrada Geral Rio dos Anjos, Morro Estevão (2a linha), Morro Estevão (3a linha), 4a linha Içara.

No trabalho rural familiar, o trabalho da criança é interpretado como ajuda à família que, embora trabalhe submetida às variações do mercado nacional e internacional, não é alvo da fiscalização do ministério do trabalho e é interpretado como um problema da cultura familiar.

Os relatórios de 13 de fevereiro de 2003 deixam transparecer a dificuldade na fiscalização da exploração infantil do trabalho considerado “informal”, realizado nas praias de Balneário Camboriú e de Florianópolis, em Santa Catarina, durante a temporada de verão. Enquanto o Grupo Especial de Combate ao Trabalho Infantil 
e Proteção ao Trabalhador (GECTIPA) solicita medidas urgentes durante o referido mês nas praias do Estado, os relatórios do dia 20 de março do mesmo ano atestam que já não é possível encontrar mais crianças trabalhando na praia durante o referido mês, o que "infelizmente, inviabiliza os adequados encaminhamentos".

Como se pode perceber, cenas de exploração infantil não são raras em Santa Catarina e muitos casos de denúncias não são registrados nos dados estaduais sobre o trabalho infantil em virtude dos limites da fiscalização. Dos 293 municípios do estado, 36 revelam situações de crianças que trabalham sendo denunciados. Somando-se a outros que aparecem no corpo dos relatórios e que não foram fiscalizados tem-se um total de 41 municípios. Conforme as descrições dos documentos, a forma do trabalho infantil não segue mais o modelo clássico dos primórdios da revolução industrial, mas combina formas híbridas em atividades geograficamente dispersas e pulverizadas. Com isso, acentuam-se os limites das políticas públicas, das fiscalizações e da legislação em coibir estratégias humanas de sobrevivência. Quantificar e qualificar as denúncias, apreender casos invisíveis e não denunciados desafia auditores fiscais e nossas pesquisas.

\section{Problemas metodológicos dos Mapas}

A pesquisa realizada durante os nossos estudos de mestrado e doutorado verificou problemas com relação à construção dos Mapas de Indicativos do Trabalho Infantil no Brasil, publicados pelo Ministério do Trabalho e do Emprego. Os problemas relacionam-se à dependência que os mapas têm de denúncias, às metodologias comparativas empregadas e aos seus limites frente às atuais tendên- 
cias do mundo do trabalho em que a atividade laboral de crianças tende a desenvolver-se em espaços privados, ilícitos ou familiares de difícil fiscalização.

Segundo um diretor de fiscalização do Ministério do Trabalho e do Emprego, atualmente, há um recuo na tendência de contratação de crianças entre cinco e 15 anos na indústria, em função das pressões internacionais e da legislação ${ }^{14}$. Além disso, conforme Soares ${ }^{15}$ (apud FSP, 2005), o problema migrou para o que ele designa de setor informal. Embora os dados do IBGE indiquem que cerca de três milhões de crianças trabalhem no país, não se sabe, exatamente, quantas estão trabalhando. $\mathrm{O}$ diretor de fiscalização do MTE afirma que o emprego na indústria era mais fácil de ser visualizado porque havia um empregador visível, identificável e a fábrica era um espaço centralizador de trabalhadores, meios e matéria-prima. $\mathrm{Na}$ atualidade, os resultados dos dados dependem das denúncias de fiscalização. Quando o trabalho infantil não é visto ou não é percebido como problema, não há denúncia e, logo, não há fiscalização.

Com base nas observações acima, problematizamos a redução anunciada. A diminuição é apenas a ponta de um imenso iceberg. É preciso ir além da aparência, descobrindo as relações sociais que ela esconde.

O trabalho infantil abordado pelo Mapa é o trabalho infantil denunciado. Para ser denunciado, ele precisa ser visualizado. Dessa forma, ficam excluídas as atividades realizadas em espaços de difícil visualização, como por exemplo, o trabalho no tráfico de drogas, o trabalho que ocorre em espaços privados e domiciliares, o trabalho na agricultura familiar cuja comunidade naturaliza a exploração da criança, o trabalho na venda de doces e de bugigangas nas sinaleiras, entre tantas outras. 
Além desses problemas mencionados é comum ocorrer uma denúncia de criança trabalhando e, na data da averiguação, os fiscais não encontrarem mais essa criança. Essa denúncia, sem flagrante, não pode ser incluída nos Mapas do governo federal. Quando comparamos o número dos municípios citados no Mapa de Indicativos de 2005 (44) com aqueles mencionados anteriormente (36) e ainda somados a outros encontrados no corpo dos relatórios (6) das denúncias, totalizam-se 86 municípios. Desses, apenas 16 coincidem com o local onde acontece a exploração do trabalho de crianças tanto nos mapas quanto nos casos de denúncia encontrados em Santa Catarina, conforme pode ser comparado com o quadro a seguir:

QUADRO 2 - Atividades econômicas exercidas por crianças e adolescentes, municípios com foco de trabalho infantil, municípios com indicativo de redução, Região Sul, Santa Catarina-2005

\begin{tabular}{|l|l|l|}
\hline \multicolumn{1}{|c|}{ ATIVIDADE } & $\begin{array}{l}\text { MUNICÍPIOS COM FOCO } \\
\text { DE TRABALHO INFANTIL }\end{array}$ & $\begin{array}{r}\text { MUNICÍPIOS COM } \\
\text { INDICATIVO DE } \\
\text { REDUÇÃO DO } \\
\text { TRABALHO INFANTIL }\end{array}$ \\
\hline Avicultura & Concórdia, Chapecó, Xanxerê & Joaçaba \\
\hline Catadores de Lixo & $\begin{array}{l}\text { Florianópolis, Joinville, } \\
\text { Blumenau, Lages, Criciúma, } \\
\text { Tijucas, Balneário Camboriú }\end{array}$ & \\
\hline Coleta de Material & $\begin{array}{l}\text { Florianópolis, Joinville, } \\
\text { Rlumenau, Lages, Criciúma, } \\
\text { Tijucas, Balneário Camboriú. }\end{array}$ & \\
\hline Comércio Ambulante & $\begin{array}{l}\text { Florianópolis, Içara, Lages, } \\
\text { Canoinhas, Ituporanga, } \\
\text { Xanxerê, Xaxim, Balneário } \\
\text { Camboriú. }\end{array}$ & $\begin{array}{l}\text { Criciúma, } \\
\text { Joinville. }\end{array}$ \\
\hline Construção Civil & \multicolumn{2}{|l}{ Blumenau, } \\
\hline
\end{tabular}




\begin{tabular}{|c|c|c|}
\hline Cultura de Batata & Papanduva, São Joaquim & $\begin{array}{l}\text { Canoinhas, Mafra, Três } \\
\text { Barras, Urubici, Urupema, } \\
\text { Pedras Grandes, Treze de } \\
\text { Maio }\end{array}$ \\
\hline Cultura de Cebola & $\begin{array}{l}\text { Imbuia, Aurora, Petrolândia, } \\
\text { Alfredo Wagner, Rancho } \\
\text { Queimado. }\end{array}$ & Ituporanga. \\
\hline Cultura de Maçã & São Joaquim, Urubici & Fraiburgo, Monte Carlo. \\
\hline Cultura de Erva-Mate & $\begin{array}{l}\text { Canoinhas, Chapecó, } \\
\text { Guatambu, Ipumirim, Irani, } \\
\text { Jaborá, Lindóia do Sul, Monte } \\
\text { Castelo, Xanxerê, Xaxim. }\end{array}$ & Irineápolis \\
\hline Cultura de Alho & Curitibanos, Friburgo, Lages. & \\
\hline Cultura de Tomate & Caçador & $\begin{array}{l}\text { Santo Amaro da Imperatriz, } \\
\text { Águas Mornas. }\end{array}$ \\
\hline $\begin{array}{l}\text { Fabricação de Artigos } \\
\text { Têxteis }\end{array}$ & Canelinha & \\
\hline Fumicultura & $\begin{array}{l}\text { Angelina, } \\
\text { Ibirama, Içara, Irani, } \\
\text { Ituporanga, José Boiteux, } \\
\text { Mirim Doce, Rio do Sul, } \\
\text { Vidal Ramos, Orleans, Taió. }\end{array}$ & \\
\hline Indústria Calçadista & São João Batista, Sombrio & \\
\hline $\begin{array}{l}\text { Indústria de } \\
\text { Esquadrias de } \\
\text { Madeira }\end{array}$ & & $\begin{array}{l}\text { Curitibanos, Chapecó, } \\
\text { Lages. }\end{array}$ \\
\hline Serviços Domésticos & Todos os municípios & \\
\hline $\begin{array}{l}\text { Serviços em } \\
\text { Cerâmicas e Olarias }\end{array}$ & $\begin{array}{l}\text { Agronômica, Aurora, } \\
\text { Itapiranga, Salete }\end{array}$ & $\begin{array}{l}\text { Canelinha, Içara, } \\
\text { Ituporanga, Rio do Sul, São } \\
\text { João Batista, Taió, Tijucas, } \\
\text { Urussanga, Treze de Maio, } \\
\text { Pedras Grandes, Jaguaruna, } \\
\text { Morro da Fumaça, Sangão } \\
\text { e Sombrio. }\end{array}$ \\
\hline
\end{tabular}

Fonte: Mapa de Indicativos do Trabalho da Criança e do Adolescente MTE/SIT (2005, p. 179). 
Também quando comparamos as atividades exercidas pode-se afirmar que são raras aquelas que coincidem. Isso significa que a diversificação e o número das atividades exercidas por crianças extrapola aquilo que a fiscalização consegue captar.

Com relação ao estado de Santa Catarina, vê-se no mapa de 2005, que os municípios listados como aqueles onde ocorre o trabalho infantil, não são, na maioria dos casos, os mesmos que aparecem na coluna referente aos municípios com indicativos de sua redução. Isso permitiria algumas leituras: somando-se uma coluna à outra, o número de municípios com indicativo de trabalho infantil nas diferentes atividades econômicas aumentaria, ressaltando-se que uns estariam apresentando persistência do trabalho infantil, enquanto esses outros municípios diferentes, embora apresentassem indicativos de redução, continuariam com foco de trabalho.

Se ainda for feito um exercício comparativo do Mapa de Indicativo de 1999 e 2005 percebe-se que os mesmos municípios com foco de trabalho infantil em 1999 permanecem em 2005 e são acrescentados outros, indicando alastramento de determinadas atividades para outros pontos do Estado, o que coloca em questão o discurso da redução.

QUADRO 3 - Atividades econômicas exercidas por crianças e adolescentes, municípios com foco de trabalho infantil, municípios com indicativo de redução, Região Sul, Santa Catarina.-1999

\begin{tabular}{|l|l|l|}
\hline $\begin{array}{l}\text { ATIVIDADE } \\
\text { ECONÔMICA }\end{array}$ & $\begin{array}{l}\text { MUNICÍPIOS COM } \\
\text { FOCO DE TRABALHO } \\
\text { INFANTIL }\end{array}$ & $\begin{array}{l}\text { MUNICÍPIOS COM } \\
\text { INDICATIVO DE } \\
\text { REDUÇÃO DO } \\
\text { TRABALHO INFANTIL }\end{array}$ \\
\hline Cultura da maçã & São Joaquim e Urubici & Fraiburgo e Monte Carlo \\
\hline Cultura do alho & $\begin{array}{l}\text { Campos Novos e Leblon } \\
\text { Régis }\end{array}$ & \\
\hline
\end{tabular}




\begin{tabular}{|c|c|c|}
\hline Cultura da erva-mate & $\begin{array}{l}\text { Canoinhas, Chapecó, } \\
\text { Guatambu, Ipumirim, Irani, } \\
\text { Jaborá, Lindóia do Sul, } \\
\text { Monte Castelo e Xanxerê }\end{array}$ & Irineápolis \\
\hline Cultura de Tomate & Rancho Queimado & Caçador \\
\hline $\begin{array}{l}\text { Venda de jornais e distribuição } \\
\text { de panfletos }\end{array}$ & & Florianópolis \\
\hline $\begin{array}{l}\text { Serviços de montagem de } \\
\text { prendedores de roupa }\end{array}$ & & $\begin{array}{l}\text { Ibicaré, Capinzal, Água Doce } \\
\text { e Correia Pinto. }\end{array}$ \\
\hline $\begin{array}{l}\text { Serviços em madeireiras e } \\
\text { serrarias }\end{array}$ & $\begin{array}{l}\text { Arabutã, Armazém, Balne- } \\
\text { ário Camboriú, Capivari de } \\
\text { Baixo,Chapecó, Concórdia, } \\
\text { Criciúma, Doutor Pedrinho, } \\
\text { Erval Velho, Florianópolis, } \\
\text { Ibirama,Grão Pará, Gravatal, } \\
\text { Lages, Mirim doce, Porto } \\
\text { União e Rio dos Cedros }\end{array}$ & $\begin{array}{l}\text { Caçador, Orleans, B. Gaivota, } \\
\text { Curitibanos, Pouso redondo e } \\
\text { Rio do Sul }\end{array}$ \\
\hline Cultura da Cebola & $\begin{array}{l}\text { Alfredo Wagner e Rancho } \\
\text { Queimado }\end{array}$ & Itapiranga \\
\hline Cultura da Batata & Papanduva & $\begin{array}{l}\text { Canoinhas, Mafra e Três } \\
\text { Barras }\end{array}$ \\
\hline Indústria Calçadista & $\begin{array}{l}\text { Braço do Norte, Nova Trento, } \\
\text { Orleans e São João Batista. }\end{array}$ & \\
\hline $\begin{array}{l}\text { Serviços em cerâmicas e } \\
\text { olarias }\end{array}$ & $\begin{array}{l}\text { Agronômica, Aurora, } \\
\text { Canelinha, Erma,Içara, } \\
\text { Itapiranga, Ituporanga, Pedras } \\
\text { grandes, Rio do Sul, Salete, } \\
\text { São Joaão Batista,Taió, } \\
\text { Tijucas, Treze de Maio, } \\
\text { Urussanga. }\end{array}$ & $\begin{array}{l}\text { Jaguaruna, Morro da Fumaça, } \\
\text { Sangão e Sombrio }\end{array}$ \\
\hline Plantio e corte de pinus & Ponte Serrada & Irani e Vargem Bonita \\
\hline
\end{tabular}

Fonte: Mapa de Indicativos do Trabalho da Criança e do Adolescente MTE/SIT (1999, p. 104-105).

Por onde quer que se empreenda a análise depara-se com informações que contradizem os limites relacionados às reduções anunciadas pelos Mapas do governo federal. Municípios não abordados em 1999 aparecem em 2005 e ainda há casos de municípios visitados em 1999 com foco de trabalho infantil e que não foram inspecionados novamente para constatar às possíveis diminuições ou o aumento. 
Assim, podemos concluir que a redução do problema da exploração do trabalho infantil anunciada pelo governo federal brasileiro é apenas a manifestação aparente de transformações no modo em que o trabalho infantil se manifesta na atualidade. $\mathrm{O}$ aumento das formas diversificadas de exploração de crianças, do desemprego e da informalidade são expressão do aumento da desigualdade social do país, onde mesmo diante da legislação proibitiva as crianças são obrigadas a trabalhar para sobreviver.

\section{Considerações finais}

Transitar nos documentos que anunciam a boa nova da erradicação da exploração do trabalho das crianças como tarefa para um futuro próximo ancorando-se, principalmente, nas mostras dos números que explicitam a sua redução, acaba por conduzir ao caminho contrário daquele que é sinalizado. O que se apreende da análise dos documentos nacionais e internacionais é uma enorme diversificação de atividades realizadas por crianças e adolescentes em diferentes espaços pulverizados e de difícil visualização, deixando exposta a dupla face do capitalismo: uma aparente benevolente que busca a todo custo reduzir as feridas e contradições do sistema, apresentando e insistindo em extensos quadros estatísticos e gráficos que estampam tal façanha. E outra face, que deixa descoberta a notável ampliação das desigualdades sociais do país. Assim, formas sofisticadas de exploração da força de trabalho são combinadas: um setor (privado, familiar, precário) interpenetra em outro (legalizado, moderno e avançado) numa simbiose perfeita, em que o moderno e rico nutre-se do atrasado e pobre, fazendo 
a desigualdade social um componente essencial da acumulação capitalista.

O que é proclamado nos Mapas de Indicativos (2005) e no Relatório Global da OIT - 2006, descortina-se na realidade vislumbrada via pesquisa junto à Superintendência Regional do Trabalho e do Emprego de Santa Catarina (SRTE/SC), responsável pela averiguação e fiscalização das condições em que as diferentes formas de trabalho se desenvolvem nesse Estado.

Se a exploração infantil no trabalho integrou a história fabril em sua origem, com as crianças e as mulheres sendo empregadas nas fábricas com jornadas longas e insalubres, hoje, são introduzidas por meio do trabalho invisível, que assume características familiares nas quais a fiscalização, a contagem e a visualização são dificultadas. A chamada reestruturação produtiva avança junto com o crescimento da subcontratação e da "informalidade", agravando a exploração da força de trabalho com a inclusão de toda a família.

A redução de focos concentradores de crianças que trabalham, coerente com as estruturas sociais desiguais do país, coincide com o aumento da exploração em espaços ilícitos. A fábrica mudou. A forma confunde. Agora, ela é dispersa e fragmentada em diferentes regiões, cidades e países. Isso posto, consideramos que não é possível afirmar a diminuição do trabalho infantil no Brasil.

\section{Referências}

ANTUNES, R. O caracol e sua concha: ensaios sobre a nova morfologia do trabalho. São Paulo: Boitempo, 2005. 
- Os caminhos da liofilização organizacional: as formas diferenciadas da reestruturação produtiva no Brasil. Idéias: Revista do Instituto de Filosofia e Ciências Humanas/Unicamp. Campinas, SP: IFCH/Unicamp, ano 9, n. 2, ano 10, n. 1, p. 13-24, 2003.

AUED, B. Desemprego e Informalização. In: KHUN, T.; SOUZA, J. Das moderne Brasilien-Gesellschaft, Politik und Kultur in der Peripherie des Westens. Bremen: V.S. Verlag, 2005.

BETTO, F. Desigualdade Social no Brasil. 2010. Disponível em: <www. amaivos.uol.com.br/amaivos09/noticia/noticia.asp?codCanal=53\&cod_ noticia $=15576>$. Acesso em: 29 mar. 2013.

BRASIL. Ministério do Trabalho e do Emprego. Mapa de Indicativos do Trabalho da Criança e do Adolescente no Brasil. 1. ed. Brasília: MTE, 2005.

CASTRO, Ramón Pena. Novamente sobre a questão do trabalho. Trabalho necessário. Rio de Janeiro: UFRJ, ano 1, n. 1, 2003. Disponível em: <http://www.uff.br/trabalhonecessário>. Acesso em: 9 maio 2007.

CONDE, Soraya F. Trabalho Invisível. 2007. Dissertação (Mestrado em Sociologia Política) - Programa de Pós-graduação em Sociologia Política/CFH, Universidade Federal de Santa Catarina, Florianópolis, 2007.

CONDE, Soraya Franzoni. A Escola e a Exploração do Trabalho Infantil na Fumicultura Catarinense. 2012. Tese (Doutorado em Educação) Universidade Federal de Santa Catarina, Florianópolis, 2012.

FRIGOTTO, G.; CIAVATTA, Maria (Orgs.). A Experiência do Trabalho e a Educação Básica. Rio de Janeiro: DP e A, 2002.

FOLHA DE SÃO PAULO. Trabalho infantil migra para o quintal. (Folha Cotidiano). São Paulo: domingo, 10 de julho de 2005.

IBGE. CNAE 2.0. (Classificação Nacional das Atividades Econômicas). Disponível em: <http//www.ibge.gov>. Acesso em: mar. 2008.

KASSOUF, A. L. Aspectos Socioeconômicos do Trabalho Infantil no 
Brasil. (Tese de pós-doutoramento do Programa de Pós-graduação em Economia da ESALQ/USP) - USP, Piracicaba, 2003.

MARX, K. Cap. VI Inédito de O Capital: Resultados do processo de produção imediato. São Paulo: Moraes. 1985.

O capital. Rio de Janeiro: Civilização Brasileira, 1998.

A Ideologia Alemã. São Paulo: Hucitec, 1989.

MDS - Ministério do Desenvolvimento Social e Combate à Fome. SAGI - Secretaria de Avaliação e Gestão da Informação. Nota Técnica 2006 SAGI/MDS. Análise dos dados sobre Trabalho Infantil na PNAD, 2005.

MESZÁROS, I. Para Além do Capital. Campinas, SP: Boitempo, 2002.

MTE - Ministério do trabalho e Emprego. SIT - Secretaria de Inspeção do Trabalho. Mapas de Indicativos do Trabalho da criança e do Adolescente 1997-1999. Brasília, 1999.

\section{. Mapas de Indicativos do Trabalho da criança e do Adolescente}

2005. Brasília, 2005.

NAVARRO, V. L. A reestruturação produtiva na indústria de calçados de couro em Franca/SP. Idéias: Revista do Instituto de Filosofia e Ciências Humanas. Campinas: Unicamp, ano 9, n. 2, ano 10, n. 1, p. 113-174, 2003.

OIT - Organização Internacional do Trabalho. O fim do trabalho infantil: um objetivo ao nosso alcance. Relatório Global no quadro do Seguimento da Declaração da OIT sobre os Princípios e Direitos Fundamentais no Trabalho, Relatório I(B), Conferência Internacional do Trabalho, 90a Sessão. Genebra, 2006.

. Um futuro sem trabalho infantil. Suplemento do Relatório Global. OIT, 2002.

OLIVEIRA, F. O Ornittorrinco. São Paulo: Boitempo. 2003

RUBIN, I. I. A teoria marxista de valor. São Paulo: Polis, 1987. 
SAINT-EXUPÉRY, Antoine de. O Pequeno Príncipe. Cap. XXI, p. 72, quando o Pequeno Príncipe encontra a raposa. Rio de Janeiro: Agir, 2006. $96 \mathrm{p}$.

VIELLA, Maria dos Anjos L Fetichismo da infância e do trabalho nos mapas do trabalho infantil. 2008.275 f. Tese (Doutorado em Educação). Universidade Federal de Santa Catarina, Florianópolis, 2008.

\section{Sites consultados:}

<http://www.dieese.org.br/esp/>. Acesso em: 21 nov. 2005.

$<$ http://www.ilo.org/public/portugue/region/ampro/brasilia/>. Acesso em: 6 jun. 2005.

\section{(Footnotes)}

1 Conforme os relatórios da inspeção grande é o número de crianças que trabalham como "chapas" nos Ceasas do estado de Santa Catarina. O "chapa" carrega caixas de frutas, verduras e legumes dos caminhões que chegam ao Ceasa, todos os dias, das 4 horas da manhã em diante.

\section{Notas}

* Professora do Instituto Federal de Educação de Santa Catarina. Doutora em Educação pela Universidade Federal de Santa Catarina e pesquisadora do Grupo de Pesquisa Sociedade, Cultura e Educação.

** Professora do Núcleo de Desenvolvimento Infantil da Universidade Federal de Santa Catarina. Doutora em Educação pela UFSC, pesquisadora do TMT (Núcleo de Estudos sobre as Transformações no Mundo do Trabalho) e atual coordenadora geral do Curso de Especialização em Docência na Educação Infantil da UFSC/MEC-SEB, edição 2012-2014.

1 Frase extraída do livro O Pequeno Príncipe, cap XXI, p. 72, quando o Pequeno Príncipe encontra a raposa. Rio de Janeiro: Agir. 2006. 96 p.

${ }^{2}$ Este texto é produto do encontro entre os resultados parciais da tese de doutorado de Viella (2008) e da dissertação de mestrado de Conde (2007), 
ambas debruçadas sobre a problemática do trabalho infantil no Brasil e sua relação com as atuais transformações no mundo do trabalho. As duas investigações foram orientadas pela professora Célia Regina Vendramini e integram as produções da pesquisa "A persistência da exploração do trabalho infantil na indústria e na agricultura catarinense" desenvolvida no Núcleo de Estudos sobre as Transformações no Mundo do Trabalho (TMT/CFH/CED/ UFSC), sob coordenação das professoras Bernardete Wrubleviski Aued e Célia Regina Vendramini.

${ }^{3}$ Nomes de alguns municípios brasileiros extraídos do Mapa de Indicativos de trabalho da criança e do adolescente.

${ }^{4}$ O IBGE/PNAD (2007) já publicou com dados mais recentes sobre a situação do trabalho infantil no Brasil. Ao analisarmos os dados, notamos que a tendência de redução verificada neste texto com os dados publicados pelo Ministério do Trabalho e do Emprego em 2005 permanece. Entretanto, os dados recentes da PNAD (2007) ainda são incompletos em relação os dados publicados pelo MTE em 2005, uma vez que este traz números regionais, locais e gerais, além da série histórica que permite uma análise mais substancial.

${ }^{5}$ Essa é a terceira edição do Mapa de Indicativos do trabalho da criança e do adolescente e corresponde à versão mais completa e atualizada publicada pelo Ministério do Trabalho e Emprego. A primeira foi publicada em 1999 e a segunda, em 2001.

${ }^{6}$ Esses dados fazem parte da tese de doutorado de Viella (2008) especialmente o Capítulo 3, Item 3.2 "Aproximando-se do fetiche da redução", p.96-102.

${ }^{7}$ De acordo com informações contidas no documento, as atualizações são até o ano de 2003, utilizando como referencial estatístico os dados da Pesquisa Nacional por Amostra de Domicílios (PNAD) de 2002, reprocessados pelo Ministério do Trabalho e Emprego para a faixa etária de cinco a quinze anos. [...].

${ }^{8} \mathrm{~A}$ OIT apresenta, anualmente, o Relatório Global dedicado a um dos temas que fazem parte da Declaração da OIT sobre os Princípios e Direitos Fundamentais no Trabalho, adotada a partir de 1998. Entre os temas está o trabalho infantil. Em 2006, o título do relatório é "A eliminação do trabalho infantil: um objetivo ao nosso alcance". Relatório Global no quadro do Seguimento da Declaração da OIT sobre os Princípios e Direitos Fundamentais no Trabalho - Conferência Internacional do Trabalho, 95a Sessão 2006, Relatório I (B), OIT, Genebra.

${ }^{9}$ Esse suplemento, preparado pelo Escritório da OIT em Brasília, oferece informações específicas sobre a situação nacional brasileira, complementares ao Relatório Global da OIT, que por limitações de cobertura de muitos países e restrições de tempo e espaço, não foram refletidas de maneira detalhada.

${ }^{10}$ Dados extraídos da dissertação de mestrado de Conde (2007, p. 43.).

${ }^{11} \mathrm{O}$ período das ocorrências aqui analisadas foi escolhido em virtude da inexistência de registros de fiscalização da exploração infantil nos anos anteriores. Conforme informações concedidas pela auditora fiscal C. S. F., os documentos referentes aos anos anteriores foram perdidos durante a última mudança de prédio. 
${ }^{12}$ Conforme os relatórios da inspeção grande é o número de crianças que trabalham como "chapas" nos Ceasas do estado de Santa Catarina. O "chapa" carrega caixas de frutas, verduras e legumes dos caminhões que chegam ao Ceasa, todos os dias, das 4 horas da manhã em diante.

13 Grupo de Combate ao Trabalho Infantil e Proteção ao Trabalhador Adolescente.

${ }^{14}$ É interessante notar que embora a legislação brasileira tenha proibido o trabalho de menores de 16 anos, salvo na condição de aprendiz, a mesma não prevê punições para os infratores e dirige os casos de trabalho infantil para medidas de proteção: encaminhamento aos pais ou responsáveis, orientação, apoio e acompanhamento temporário, matrícula e frequência obrigatória em instituições de ensino, inclusão em programa comunitário, requisição de tratamento médico, psicológico, psiquiátrico, abrigo em entidade, colocação em família substituta, inclusão em programa oficial ou comunitário de auxílio no tratamento a alcoólatras e toxicômacos.

${ }^{15}$ Diretor de Fiscalização do MTE, em entrevista concedida ao Jornal Folha de São Paulo em 10 de julho de 2005. 
